\title{
Die Nachrichtenjournale tagesthemen und heute journal
}


Johannes Mehne

\section{Die Nachrichtenjournale tagesthemen \\ und heute journal}

是 Springer VS 
Johannes Mehne

Berlin, Deutschland

ISBN 978-3-658-01649-4

ISBN 978-3-658-01650-0 (eBook)

DOI 10.1007/978-3-658-01650-0

Die Deutsche Nationalbibliothek verzeichnet diese Publikation in der Deutschen Nationalbibliografie; detaillierte bibliografische Daten sind im Internet über http://dnb.d-nb.de abrufbar.

Springer VS

(C) Springer Fachmedien Wiesbaden 2013

Das Werk einschließlich aller seiner Teile ist urheberrechtlich geschützt. Jede Verwertung, die nicht ausdrücklich vom Urheberrechtsgesetz zugelassen ist, bedarf der vorherigen $\mathrm{Zu}$ stimmung des Verlags. Das gilt insbesondere für Vervielfältigungen, Bearbeitungen, Übersetzungen, Mikroverfilmungen und die Einspeicherung und Verarbeitung in elektronischen Systemen.

Die Wiedergabe von Gebrauchsnamen, Handelsnamen, Warenbezeichnungen usw. in diesem Werk berechtigt auch ohne besondere Kennzeichnung nicht zu der Annahme, dass solche Namen im Sinne der Warenzeichen- und Markenschutz-Gesetzgebung als frei zu betrachten wären und daher von jedermann benutzt werden dürften.

Gedruckt auf säurefreiem und chlorfrei gebleichtem Papier

Springer VS ist eine Marke von Springer DE. Springer DE ist Teil der Fachverlagsgruppe Springer Science+Business Media.

www.springer-vs.de 


\section{Geleitwort}

Nachrichtenjournale sind die journalistischen Visitenkarten der großen Fernsehsender. Für die tagesthemen und das heute journal bündeln die öffentlichrechtlichen Fernsehsender ihre Kompetenz. Ob Auslands-Korrespondenten oder innenpolitische Beitragsautoren - die journalistische Elite soll (und will) in diesen Sendungen präsent sein. Der Anspruch beider Redaktionen ist, den Formaten eine eigene, unverwechselbare Handschrift zu verleihen. Diese unterscheidet sich deutlich von den sogenannten Hauptnachrichtensendungen tagesschau und heute.

Wenn die Nachrichtenjournale eine solch herausragende Bedeutung für die Sender haben, lohnt sich ein intensiver Blick auf ihre Formatstruktur. Welche Formatelemente charakterisieren heute journal und tagesthemen? Was unterscheidet die beiden journalistischen Aushängeschilder von ARD und ZDF? Welche Kriterien bestimmen die Themenauswahl? Warum haben sich die Redaktionen für ihr jeweiliges Studiosetting entschieden? Was sind die Aufgaben der Moderatoren? Welche (auch crossmedialen) Veränderungen und Entwicklungen der Nachrichtenjournale sind denkbar und erwünscht? Und damit insgesamt: Welches Selbstverständnis liegt den beiden Formaten zugrunde?

Diesen Fragen (und ausdrücklich nicht einem Vergleich von Sendeplätzen, Konkurrenz-Programmen und Marktanteilen) geht Johannes Mehne in seiner Bachelor-Arbeit nach. In Ergänzung zu einer ersten, inhaltsanalytischen Beschreibung der Formate ist es ihm gelungen, Leitfadeninterviews mit kompetenten Gesprächspartnern zu führen. Zur Ausrichtung der tagesthemen haben u. a. Ulrich Deppendorf als Studioleiter und Chefredakteur Fernsehen im ARDHauptstadtstudio, die Moderatoren Caren Miosga und Tom Buhrow sowie Dr. Kai Gniffke, Chefredakteur von ARD-aktuell, ausführlich Stellung bezogen. Zum heute journal äußern sich u. a. Moderator Dr. Claus Kleber, Redaktionsleiterin Anne Reidt und der Leiter der Hauptredaktion Aktuelles, Elmar Theveßen.

Vor allem durch diese Leitfadeninterviews wird klar, wie groß die Differenzen im Selbstverständnis zwischen reinen Nachrichtenformaten und Nachrichtenjournalen sind und wie die Macher ihre jeweilige Sendung in Gegenwart und Zukunft positionieren wollen.

Natürlich gibt es perspektivisch noch viele weitere inhaltliche und methodische Ansätze zur Analyse von tagesthemen, heute journal und Nachrichtenjournalen insgesamt. Johannes Mehne leistet mit dieser Arbeit aber einen wertvollen 
Beitrag zur grundsätzlichen, differenzierten Betrachtung des Selbstverständnisses der öffentlich-rechtlichen Nachrichtenjournale. Damit gibt er zugleich Anstöße zu weiterer, notwendiger Formatforschung, etwa mit Blick auf die entsprechenden Angebote der Privatsender.

Dortmund, im Januar 2013

Professor Dr. Michael Steinbrecher 


\section{Inhaltsverzeichnis}

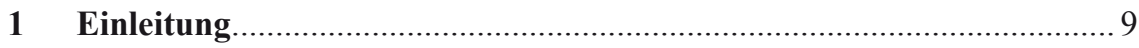

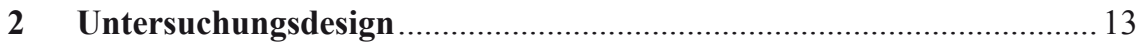

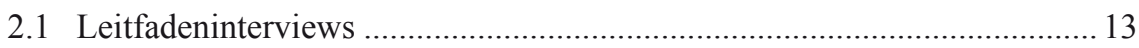

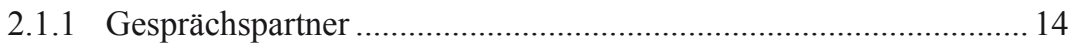

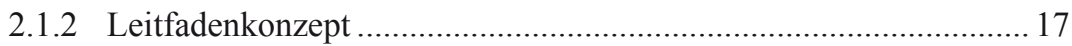

2.1.3 Durchführung und Auswertung ................................................... 18

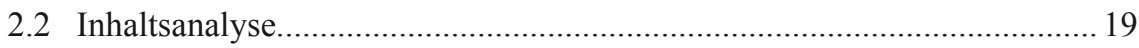

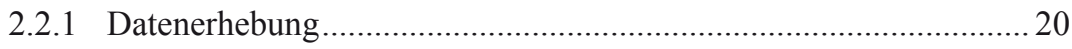

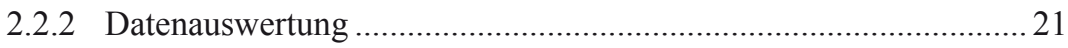

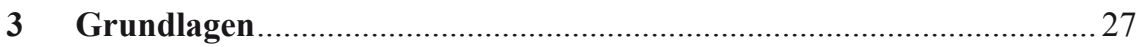

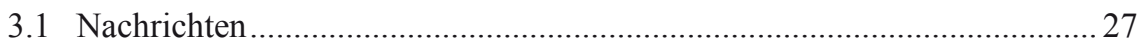

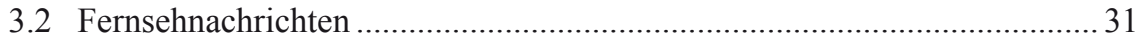

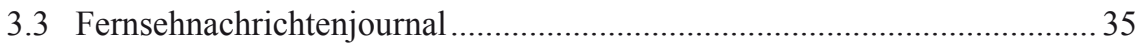

4 Die Marken tagesthemen und heute journal......................................... 43

4.1 tagesthemen ..................................................................................... 43

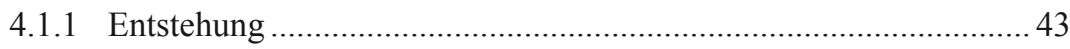

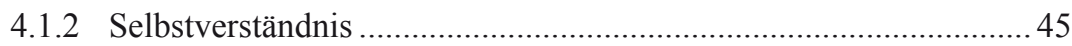

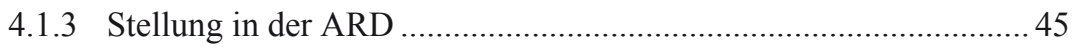

4.1.4 Abgrenzung zur tagesschau ........................................................ 47

4.1.5 Vergleich mit dem heute journal ................................................... 48

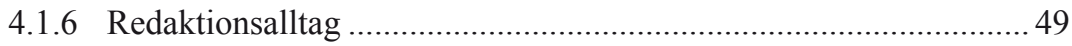

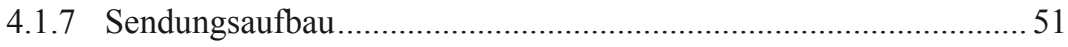

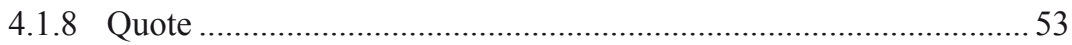

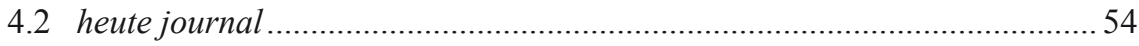

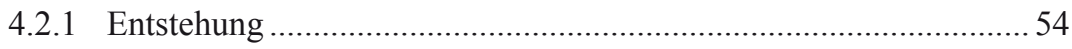




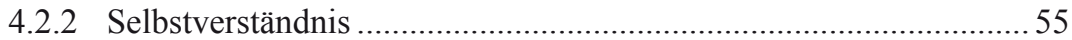

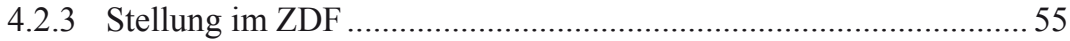

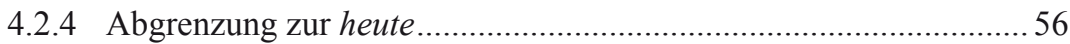

4.2.5 Vergleich mit den tagesthemen ....................................................... 58

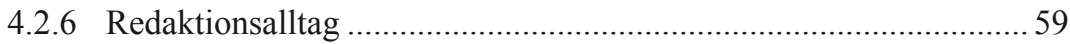

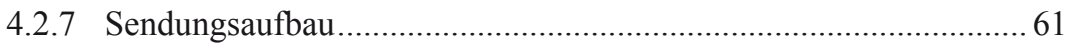

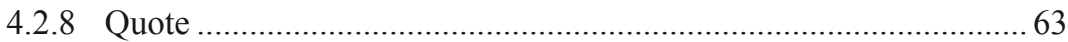

5 Inhalt und Präsentation der Nachrichtenjournale................................. 65

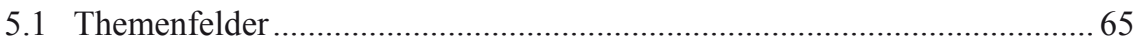

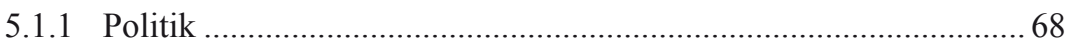

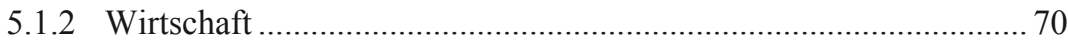

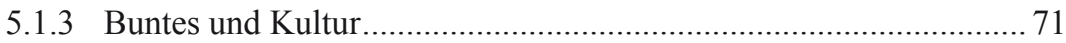

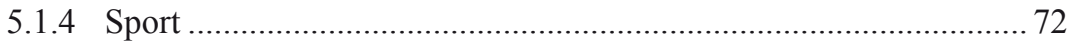

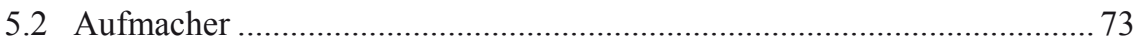

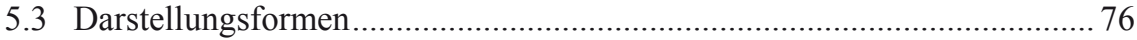

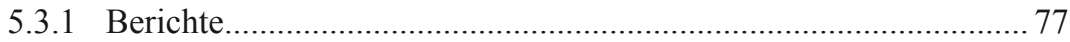

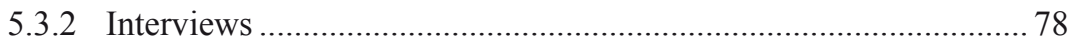

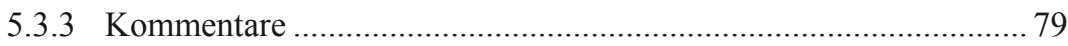

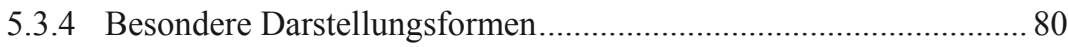

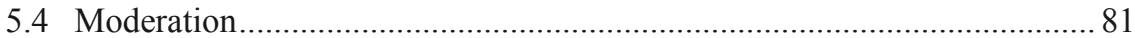

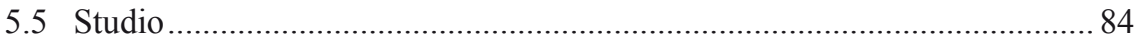

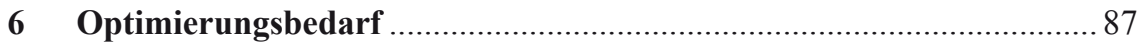

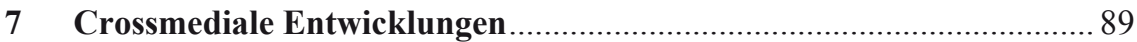

8 Zusammenfassung und Ausblick ....................................................... 93

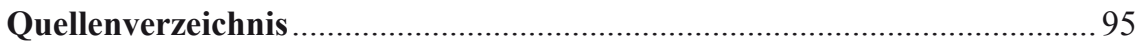

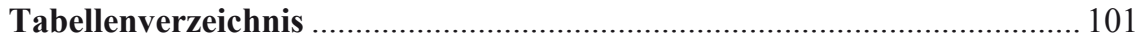

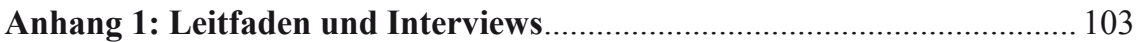

Anhang 2: Codebuch und Codierbogen..................................................... 193 